\title{
Produção de forragem e características da estrutura do dossel de cultivares de Brachiaria brizantha sob pastejo
}

\author{
Valéria Pacheco Batista Euclides(1), Manuel Cláudio Motta Macedo(1), Cacilda Borges do Valle(1), \\ Rodrigo Amorim Barbosa(1) e Welhington Velasques Gonçalves ${ }^{(1)}$
}

(1)Embrapa Gado de Corte, Caixa Postal 154, CEP 79002-970 Campo Grande, MS. E-mail: val@cnpgc.embrapa.br, macedo@cnpgc.embrapa. br, cacilda@cnpgc.embrapa.br, rodrigo@cnpgc.embrapa.br, vardiiii@hotmail.com

Resumo - O objetivo deste trabalho foi avaliar o efeito do pastejo animal sobre a produção de forragem e sobre os componentes estruturais dos pastos das cultivares Marandu, Xaraés e Piatã de Brachiaria brizantha. O delineamento experimental foi o de blocos ao acaso, com três tratamentos e duas repetições. Os piquetes com 2 ha foram subdivididos em dois e submetidos a pastejo alternado, com 28 dias de utilização e 28 dias de diferimento. Foram utilizados três animais avaliadores por piquete, e animais reguladores foram adicionados e retirados de cada piquete, para manter resíduos pós-pastejo em torno de $3 \mathrm{Mg} \mathrm{ha}^{-1}$ de matéria seca. Os pastos foram amostrados, no pré e no pós-pastejo, a fim de se estimarem a massa de forragem e a proporção dos componentes morfológicos. A massa de forragem no pré-pastejo foi superior para a cultivar Xaraés, quando comparada à Marandu; a cultivar Piatã apresentou massa semelhante às das outras duas. As principais diferenças nas estruturas dos dosséis, entre as cultivares, foram acúmulo de colmo e, conseqüentemente, redução na relação lâmina foliar:colmo, na cultivar Piatã no período das águas e na Xaraés no período seco, o que indica que o manejo do pastejo deve ser diferenciado para essas cultivares. À semelhança da 'Marandu', as cultivares Xaraés e Piatã são bem adaptadas aos solos do Cerrado e são alternativas à diversificação de forragem.

Termos para indexação: acúmulo de lâmina foliar, adubação de manutenção, capim-braquiária, Cerrado, componente morfológico, época de florescimento.

\section{Forage yield and sward structure characteristics of Brachiaria brizantha cultivars under grazing}

\begin{abstract}
The objective of this work was to evaluate the animal grazing effect on forage yield and on the pasture structural characteristics of cultivars Marandu, Xaraés and Piatã of Brachiaria brizantha. The experimental design was a randomized complete block, with three treatments and two replicates. The paddocks ( 2 ha) were divided into two, and submitted to alternated grazing, with 28 days of grazing and 28 days of rest. Evaluations were made with three tester steers per paddock, and additional steers were added and removed from each paddock, to ensure post-grazing residues of about $3 \mathrm{Mg} \mathrm{ha}^{-1}$ dry matter. All pastures were sampled, before and after grazing, in order to estimate forage mass and percentages of the morphological components. The pre-grazing forage mass for 'Xaraés' pasture was greater than for 'Marandu'. 'Piatã' had pre-grazing forage mass similar to the others. The main differences in the sward structures between cultivars were stem accumulation and, consequently, the reduction in the leaf blade:stem ratio, in 'Piatã' during the rainy season and in 'Xaraés' during the dry season, which suggests different grazing management for these cultivars. Similarly to 'Marandu', Piatã and Xaraés cultivars are well adapted to Cerrado soils, and are new alternatives for forage diversification.

Index terms: leaf lamina accumulation, maintenance fertilization, palisade grass, Cerrado, morphological component, flowering time.
\end{abstract}

\section{Introdução}

Estima-se que $50 \%$ das áreas de pastagens cultivadas na região Centro-Oeste (Macedo, 2005) e 65\% na região Norte (Dias-Filho \& Andrade, 2005) são formadas por Brachiaria brizantha cultivar Marandu. A excelente adaptação dessa cultivar às condições brasileiras, não impediu que, a partir de 1994, passasse a ocorrer morte de pastos de capim-marandu, com prejuízos econômicos expressivos ao setor pecuário dos estados do Acre, Pará, Rondônia (Andrade \& Valentim, 2004), Mato Grosso, Maranhão e Tocantins (Valle et al., 2000). Segundo Barbosa (2006), esse problema temse constituído em importante causa de degradação dos pastos, e o principal fator envolvido na síndrome da morte do capim-marandu. Esse fato indica que deve ser dada 
mais ênfase às pesquisas, a fim de desenvolver novas opções forrageiras para maior diversificação das espécies utilizadas.

Resultados de avaliações em parcelas - envolvendo entre 200 e 300 acessos de Brachiaria spp., em Campo Grande, MS, e em Planaltina, DF - permitiram selecionar ecótipos de maior produtividade e menor estacionalidade do que as cultivares tradicionais (Valle \& Miles, 1994). Desses acessos, os 19 melhores foram avaliados em Rede de Ensaios Regionais, e selecionados os oito melhores da análise conjunta entre locais, que foram avaliados sob pastejo, em pequenas parcelas, dos quais quatro acessos se mostraram promissores e bem adaptados à região do Cerrado (Euclides et al., 2000). Todavia, nessas duas etapas de seleção, as respostas obtidas são exclusivamente relacionadas às plantas forrageiras. Assim, como parte da proposta de lançamento de cultivares de forrageiras adotadas pela Embrapa Gado de Corte, faz-se necessário, a avaliação em condições similares ao sistema de produção (Euclides \& Euclides Filho, 1998). A partir daí, segue-se uma terceira fase quando acessos são avaliados considerando-se a existência de dois sistemas bem definidos - o pasto e o animal - e sua interação.

O objetivo deste trabalho foi avaliar o efeito do pastejo sobre a produção de forragem e sobre as características estruturais das cultivares Marandu, Xaraés e Piatã de Brachiaria brizantha.

\section{Material e Métodos}

Este experimento foi conduzido na Embrapa Gado de Corte $\left(20^{\circ} 27^{\prime} \mathrm{S}, 54^{\circ} 37^{\prime} \mathrm{W}\right.$ e altitude de $\left.530 \mathrm{~m}\right)$, Campo Grande, MS, de maio de 2001 a abril de 2004. O padrão climático da região é descrito, segundo Köppen, como pertencente à faixa de transição entre Cfa e Aw tropical úmido. A precipitação média anual é de $1.560 \mathrm{~mm}$, e o período considerado de seca é de maio a setembro (30\% da precipitação anual). As temperaturas e as precipitações médias do período experimental encontram-se na Figura 1, e o balanço hídrico na Figura 2.

O solo da área experimental é classificado como Latossolo Vermelho distrófico, com teores de argila entre 36 e 41\% (Embrapa, 1999). Em janeiro de 2000, a área experimental foi corrigida e adubada com $3 \mathrm{Mg} \mathrm{ha}^{-1}$ de calcário dolomítico $(\mathrm{PRNT}=75 \%)$, $80 \mathrm{~kg} \mathrm{ha}^{-1}$ de $\mathrm{P}_{2} \mathrm{O}_{5}$ e de $\mathrm{K}_{2} \mathrm{O}$, e $32 \mathrm{~kg} \mathrm{ha}^{-1}$ de FTE BR-12. Em março do mesmo ano, foram semeados $2,2 \mathrm{~kg} \mathrm{ha}^{-1} \mathrm{de}$ sementes puras viáveis das cultivares Marandu, Xaraés e Piatã de Brachiaria brizantha. Depois da cobertura das sementes com passagem de grade niveladora fechada, procedeu-se à compactação do solo com um rolo compactador. Em julho, foi realizada capina manual de invasoras e, em outubro, foram construídas as cercas e instalados os bebedouros. Em janeiro de 2001, procedeu-



Figura 1. Temperaturas máxima, média e mínima e distribuição da precipitação pluvial (PPT) e umidade relativa (UR) do ar, de maio de 2001 a abril de 2004. 
se corte de uniformização, a $20 \mathrm{~cm}$ do solo, com segadeira, e aplicados em seguida $99 \mathrm{~kg} \mathrm{ha}^{-1}$ de $\mathrm{N}$ na forma de uréia. Em março e abril, foi feito pastejo de uniformização e, no mês seguinte, iniciaram-se as avaliações.

De outubro a novembro de cada ano, foram aplicados, em cobertura, $40 \mathrm{~kg} \mathrm{ha}^{-1}$ de $\mathrm{P}_{2} \mathrm{O}_{5}$ e de $\mathrm{K}_{2} \mathrm{O}$ e, do mesmo modo, em novembro a dezembro foram aplicados $50 \mathrm{~kg} \mathrm{ha}^{-1}$ de N, na forma de uréia. Em dezembro de 2003, foram aplicados, em cobertura, $2 \mathrm{Mg}$ ha $^{-1}$ de calcário dolomítico (PRNT $=75 \%$ ), a fim de manter os níveis de saturação por bases do solo acima de $40 \%$.

O delineamento experimental foi o de blocos ao acaso, com três tratamentos e duas repetições. Os tratamentos foram dois ecótipos de $B$. brizantha, B178 (cultivar Xaraés) e B112 (cultivar Piatã) e, como testemunha, foi utilizada a B. brizantha cultivar Marandu.

Os piquetes de 2 ha foram subdivididos em dois e submetidos ao pastejo alternado, com 28 dias de utilização e 28 dias de descanso. Cada piquete foi pastejado por três novilhos (animais avaliadores) distribuídos ao acaso. Animais reguladores da mesma categoria foram colocados e removidos de cada piquete, de acordo com a disponibilidade de forragem, o que assegurou, entre os tratamentos, resíduo pós-pastejo em torno de $3 \mathrm{Mg} \mathrm{ha}^{-1}$ de matéria seca. Anualmente, em maio, os animais foram substituídos por outros animais da mesma categoria.

Os pastos foram amostrados no pré e no pós-pastejo. Para se estimar a massa de forragem, foram cortadas ao nível do solo 40 amostras de $1 \mathrm{~m}^{2}$, em cada piquete, que foram divididas em duas subamostras: uma foi secada e pesada, e a outra foi separada em lâmina foliar, colmo (bainha e colmo) e material morto. A proporção de cada componente morfológico foi expressa como percentagem do peso total.

O acúmulo de lâmina foliar foi obtido a partir da diferença entre a massa de lâmina foliar no pré-pastejo

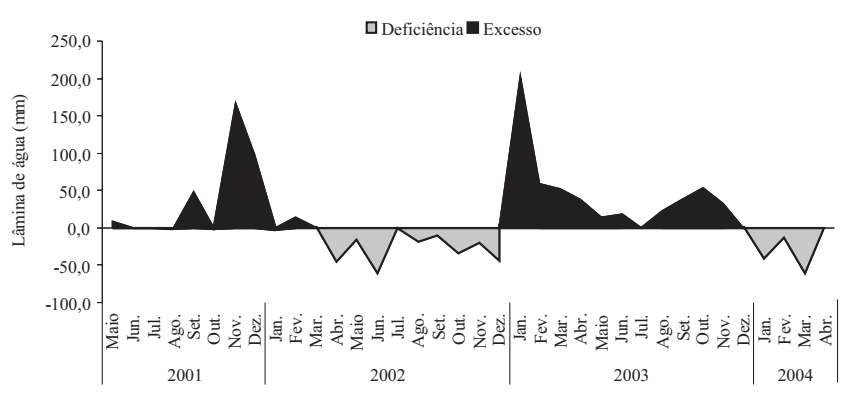

Figura 2. Balanço hídrico mensal de maio de 2001 a abril de 2004. atual e a massa de lâmina foliar no pós-pastejo do ciclo de pastejo anterior. Esse valor foi dividido pelo número de dias de acúmulo (28 dias) para obtenção da taxa média de acúmulo de lamina foliar (TALF) para cada ciclo de pastejo.

As amostras de solo foram feitas em janeiro de 2000, quando se iniciou o preparo do solo, e no final do período chuvoso de cada ano, entre maio e junho. As amostras foram coletadas na camada de $0-20 \mathrm{~cm}$ do solo, em três faixas eqüidistantes ao longo dos piquetes. Cada faixa foi amostrada em 15 posições, a fim de compor uma amostra composta. As análises químicas do solo foram realizadas de acordo com a metodologia proposta em Embrapa (1997).

Em janeiro, abril, julho e outubro, foram coletadas lâminas foliares da folha índice, segundo critério proposto por Macedo (1997). A coleta foi efetuada ao acaso, em 30 posições por piquete. Para a avaliação de $\mathrm{P}$, utilizou-se de digestão nítrico-perclórica do tecido vegetal, e de determinação analítica por colorimetria do metavanadato, segundo Malavolta et al. (1997).

Para a análise estatísticas, os dados foram agrupados por épocas do ano, de maio a setembro (período seco) e de outubro a abril (período das águas), e analisados por um modelo matemático com efeito aleatório de bloco e os efeitos fixos de tratamento, período do ano, ano de avaliação e suas interações. Todas as análises foram feitas pelo método dos quadrados mínimos utilizandose o procedimento "General Linear Model" (SAS Institute, 1996). Os comandos RANDOM e TEST foram utilizados para a identificação e realização dos testes apropriados para cada variável dependente. A comparação de médias foi realizada pelo teste Tukey, a 5\% de probabilidade. No caso de interações significativas, a comparação de média foi realizada por meio da probabilidade da diferença e pelo teste $\mathrm{t}$, a $5 \%$ probabilidade.

Para os acúmulos de lâmina foliar, o mês foi analisado como variável contínua. Com base em análises prévias, selecionou-se a polinomial de maior ordem.

\section{Resultados e Discussão}

A massa de forragem do pré-pastejo foi superior $(\mathrm{p}<0,05)$ para a cultivar Xaraés, quando comparada à cultivar Marandu; já a cultivar Piatã apresentou massa semelhante aos outros dois. A massa de forragem média das cultivares Xaraés, Piatã e Marandu, no pré-pastejo, 
foi, respectivamente, $4.075,3.850$ e $3.730 \mathrm{~kg} \mathrm{ha}^{-1}$ de matéria seca (MS). A massa de forragem foi maior $(\mathrm{p}<0,01)$ durante o período das águas, quando comparada ao período seco. Também houve interação $(\mathrm{p}<0,05)$ entre cultivar e período do ano (Tabela 1). Foi, também, observada diferença entre anos $(p<0,01)$, sendo as massas de forragens semelhantes nos dois primeiros anos e essas superiores à do terceiro ano, com as médias, respectivamente, de 4.020, $3.940 \mathrm{e}$ $3.680 \mathrm{~kg} \mathrm{ha}^{-1}$ de MS. No entanto, não houve interações envolvendo os efeitos de cultivar e de ano experimental $(\mathrm{p}=0,32)$ e os efeitos de cultivar, de período do ano e de ano experimental $(\mathrm{p}=0,46)$.

Essas diferenças da massa de forragem podem, em parte, ser explicadas pelas diferenças na taxa de acúmulo de lâmina foliar (TALF), uma vez que houve tendência $(\mathrm{p}=0,07)$ de maior TALF para a cultivar Xaraés, quando comparada à cultivar Marandu, sendo a TALF da cultivar Piatã semelhante às outras duas cultivares. As médias foram de 28,25 e $22 \mathrm{~kg} \mathrm{ha}^{-1}$ por dia de MS, para as cultivares Xaraés, Piatã e Marandu, respectivamente. Também foi observada tendência $(\mathrm{p}=0,09)$ de maiores TALF nos dois primeiros anos, e essas foram superiores à do terceiro ano, sendo as médias de 30,28 e $24 \mathrm{~kg} \mathrm{ha}^{-1}$ por dia de MS, no primeiro, segundo e terceiro ano, respectivamente. E ainda durante o período das águas a TALF foi superior $(\mathrm{p}=0,01)$ à do período seco; as médias foram, respectivamente, 41 e $9 \mathrm{~kg} \mathrm{ha}^{-1}$ por dia de MS.

Quando na análise da TALF, o mês do ano foi considerado como variável contínua, houve interação $(p=0,04)$ entre os efeitos de cultivares e ano experimental. Independentemente da cultivar e do ano experimental, a curva que melhor ajustou foi a cúbica $(\mathrm{p}=0,01)$, as maiores TALF foram observadas nos meses de verão, as intermediárias nos meses de primavera e outono e as muito baixas nos meses de inverno (Figura 3). Esse padrão de variação no acúmulo de forragem é típico das regiões tropicais, conseqüência da estacionalidade das chuvas, além de variações de temperatura (Figura 1) e de fotoperíodo. Desta forma, comportamentos semelhantes foram observados para os acúmulos líquidos de lâminas foliares em capimmarandu (Zeferino, 2006; Lara, 2007) e em capimxaraés (Rodrigues, 2004; Lara, 2007).

Ao analisar os dois primeiros anos, observa-se que a cultivar Xaraés acumulou mais LF durante o verão do que as outras duas. No terceiro ano, a TALF foi semelhante para as três cultivares. Ressalta-se que, apesar do menor acúmulo de LF para as três cultivares, durante o terceiro ano experimental (2003/2004), o efeito da estacionalidade da TALF foi menor (Figura 3). Provavelmente, isso pode ser explicado pelas maiores precipitações no inverno e na primavera, quando comparados aos mesmos períodos dos anos anteriores (Figuras 1 e 2). Por outro lado, a precipitação foi baixa durante o verão que, aliada às altas temperaturas, resultou em deficit hídrico (Figura 2) e, conseqüentemente, menor TALF durante esse período, quando comparado ao mesmo período dos anos anteriores (Figura 3).

Ressalta-se, ainda, que não houve limitação de temperatura para o crescimento das plantas, ao longo dos três anos experimentais, sendo a média das temperaturas mínimas superiores a $16^{\circ} \mathrm{C}$, com exceção dos períodos de maio a julho (Figura 1). Segundo Alcântara et al. (1993), temperaturas mínimas inferiores a essa inibem o crescimento das forrageiras tropicais.

Independentemente da cultivar, foi observada queda nas taxas de acúmulo de forragem, provavelmente em conseqüência dos teores de $\mathrm{P}$ no solo abaixo do patamar considerado adequado para manter a taxa de crescimento das forrageiras, principalmente na camada de 0-20 cm de profundidade, com teores de $\mathrm{P}$ de 3,5, 2,5, 2,3, 1,7 e $1,8 \mathrm{mg} \mathrm{dm}^{-3}$ no extrator de Mehlich-1, nos anos de

Tabela 1. Médias dos quadrados mínimos e os erros-padrão da média (EPM) para as massas de matéria seca (MMS) e de matéria seca de lâminas foliares (MSLF), as percentagens de lâminas foliares (LF), de colmos (Co) e de material morto (MM), e a relação entre lâmina foliar:colmo (LF:Co), no pré-pastejo, dos pastos de $B$. brizantha cultivares Marandu, Xaraés e Piatã, de acordo com o período do ano ${ }^{(1)}$.

\begin{tabular}{|c|c|c|c|c|c|c|c|c|}
\hline \multirow[t]{2}{*}{ Variável } & \multicolumn{4}{|c|}{ Período das águas } & \multicolumn{4}{|c|}{ Período seco } \\
\hline & Marandu & Piatã & Xaraés & EPM & Marandu & Piatã & Xaraés & EPM \\
\hline MMS (kg ha-1) & $3.850 \mathrm{~b}$ & $3.980 \mathrm{ab}$ & $4.260 \mathrm{a}$ & 45 & $3.605 \mathrm{a}$ & $3.720 \mathrm{a}$ & $3.890 \mathrm{a}$ & 53 \\
\hline $\operatorname{MSLF}\left(\mathrm{kg} \mathrm{ha}^{-1}\right)$ & $1.530 \mathrm{~b}$ & $1.650 \mathrm{ab}$ & $1.845 \mathrm{a}$ & 27 & $720 b$ & $930 \mathrm{a}$ & $660 \mathrm{~b}$ & 32,1 \\
\hline LF (\%) & $39,4 a$ & $41,3 \mathrm{a}$ & $42,5 \mathrm{a}$ & 0,60 & $19,9 \mathrm{ab}$ & $25,2 \mathrm{a}$ & $16,7 \mathrm{~b}$ & 0,71 \\
\hline Co $(\%)$ & $22,8 \mathrm{c}$ & $29,3 a$ & $25,5 b$ & 0,27 & $28,0 \mathrm{~b}$ & $27,9 b$ & $31,3 \mathrm{a}$ & 0,32 \\
\hline MM (\%) & $37,8 \mathrm{a}$ & $29,4 b$ & $32,0 \mathrm{ab}$ & 0,44 & $51,9 \mathrm{a}$ & $46,9 b$ & $52,0 \mathrm{a}$ & 0,52 \\
\hline $\mathrm{LF}: \mathrm{Co}$ & $1,89 \mathrm{a}$ & $1,62 b$ & $1,89 \mathrm{a}$ & 0,02 & $0,78 b$ & $0,96 \mathrm{a}$ & $0,64 b$ & 0,02 \\
\hline
\end{tabular}

${ }^{(1)}$ Médias seguidas de letras iguais na linha, dentro de período do ano, não diferem entre si pelo teste de Tukey, a 5\% de probabilidade. 
2000, 2001, 2002, 2003 e 2004, respectivamente. Esses valores estão abaixo dos sugeridos para manutenção de Brachiaria brizantha, que seriam no mínimo de $80 \%\left(3,3\right.$ a $\left.4,8 \mathrm{mg} \mathrm{dm}^{-3}\right)$ dos valores estipulados para o estabelecimento $\left(4,1\right.$ a $\left.6 \mathrm{mg} \mathrm{dm}^{-3}\right)$ dessa espécie forrageira, nessa classe de textura de solo (Macedo, 2004). Na camada de $0-10 \mathrm{~cm}$ de profundidade, em razão das adubações anuais de manutenção, os teores de $P$ variaram entre os anos de 2002, 2003 e 2004, e foram de $3,8,4,5$ e $5,5 \mathrm{mg} \mathrm{dm}^{-3}$ no extrator de Mehlich-1, respectivamente, o que demonstra acúmulo natural nas camadas superiores do solo em conseqüência das aplicações superficiais do fertilizante em cobertura e reciclagem pela planta. Esses resultados sugerem que para essa espécie forrageira manter taxas de crescimento, e conseqüentemente a produção animal estável ao longo dos anos, com o ajuste adequado da lotação, as adubações anuais de manutenção de P são indispensáveis e devem ser superiores às utilizadas neste trabalho. Por outro lado,
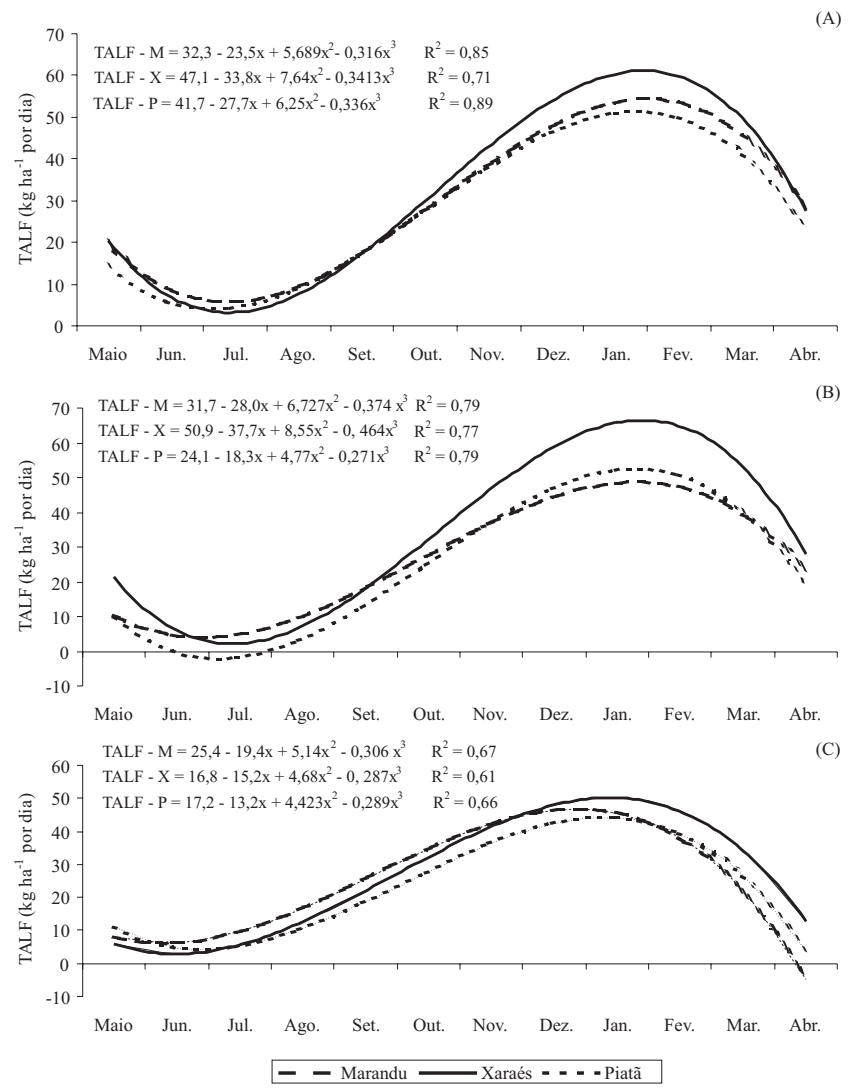

Figura 3. Taxa de acúmulo de lâmina foliar (TALF) de pastos de $B$. brizantha cultivares Marandu (M), Xaraés (X) e Piatã (P), de acordo com os meses do ano e ano experimental: 2001/2002 (A), 2202/2003 (B) e 2003/2004 (C). saturação por bases (V) do solo, antes da implantação do experimento, era inferior a $20 \%$, e foi mantida acima de $30-35 \%$, na camada de $0-20 \mathrm{~cm}$ de profundidade. Os valores médios de $\mathrm{V} \%$, nessa camada, variaram de $39,32,42,31$ e $38 \%$ nos anos de 2000, 2001, 2002, 2003 e 2004, respectivamente. Vale ressaltar que houve reaplicação de calcário em cobertura 2003. Esses teores, segundo Vilela et al. (2004), estão de acordo com os níveis de exigência para essa forrageira.

Um indicador da manutenção adequada dos teores de nutrientes na planta, foi observado quanto aos teores de P nas lâminas foliares das folhas índices, entre 2002 e 2004. Os valores observados estiveram, em média, sempre acima de $1,5 \mathrm{~g} \mathrm{~kg}^{-1}$ de $\mathrm{P}$ na matéria seca foliar (Figura 4), e, portanto, acima do nível crítico e na faixa recomendada para essa espécie por Monteiro (2005).

Ao analisar os componentes morfológicos das plantas, observam-se algumas diferenças ao longo do ano, no entanto, eles foram semelhantes $(\mathrm{p}>0,05)$ entre os anos experimentais (Tabela 1). Houve interação entre cultivar e estação do ano $(\mathrm{p}<0,05)$ para as percentagens de lâmina foliar (PLF), de colmo (PCo) e de material morto (PMM), gerando, desta forma, dosséis de estruturas diferentes.

As três cultivares apresentaram PLF semelhantes $(\mathrm{p}=0,15)$, durante o período das águas. No entanto, durante o período seco, a cultivar Piatã apresentou maior $(p<0,05)$ PLF do que a cultivar Xaraés. Já para a cultivar Marandu a PLF foi intermediária. No período das águas a PCo foi maior $(\mathrm{p}<0,05)$ para cultivar Piatã, seguidas da cultivares Xaraés e Marandu, que resultou em menor $(\mathrm{p}>0,05)$ relação $\mathrm{LF}$ :Co para $\mathrm{o}$ pasto de Piatã e maiores para os pastos de Marandu e Xaraés (Tabela 1). A maior $(\mathrm{p}=0,02)$ massa de colmo, observada na cultivar Xaraés (1.110 $\mathrm{kg} \mathrm{ha}^{-1}$ de colmo) - quando comparada à cultivar Marandu $\left(890 \mathrm{~kg} \mathrm{ha}^{-1}\right.$

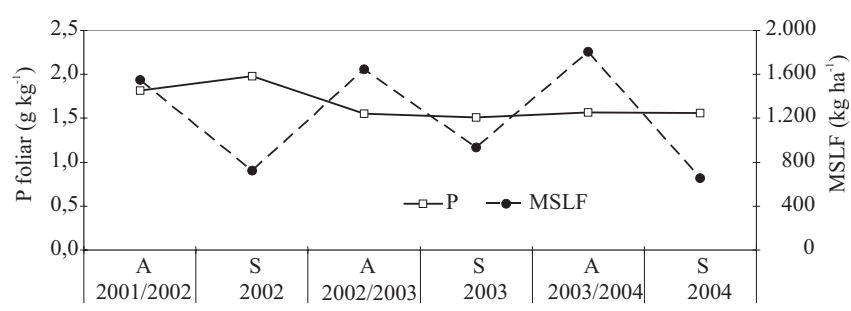

Figura 4. Teores médios de $\mathrm{P}$ foliar na folha-índice e massa de matéria seca de lâminas foliares (MSLF) de B. brizantha cultivares Marandu, Xaraés e Piatã, nos períodos das águas (A) e da seca (S), submetidas a pastejo e com adubação anual de manutenção. 
de colmo), durante o período das águas - indica que o período de descanso foi longo para essa cultivar. Isso pôde ser confirmado pelos resultados obtidos por Pedreira et al. (2007), durante o período das águas, quando maior acúmulo de colmo foi observado para a cultivar Xaraés manejada a 28 dias de intervalo entre pastejo, comparada a 22 dias $(95 \%$ interceptação luminosa). Durante o período seco, a maior $(p<0,05)$ PCo foi observada para a cultivar Xaraés quando comparada às outras cultivares; conseqüentemente a relação LF:Co foi maior para a Piatã comparada às outras cultivares. Ademais, no período das águas, o pasto de Marandu apresentou maior $(\mathrm{p}<0,05)$ PMM do que a cultivar Piatã, sendo a cultivar Xaraés intermediária. Já no período seco, o comportamento foi o inverso a da cultivar Piatã que apresentou menor $(\mathrm{p}<0,05)$ PMM do que as outras cultivares.

Vários autores ressaltaram a importância da presença de colmo e de material morto modificando a estrutura do dossel e, conseqüentemente, o desempenho animal (Brâncio et al., 2003; Rego et al., 2006; Euclides et al., 2007, 2008). Essas diferenças nas estruturas dos dosséis podem ser, em parte, explicadas pela época de florescimento das cultivares. Em Campo Grande (latitude $20^{\circ} 27^{\prime} \mathrm{S}$ ), o florescimento da cultivar Piatã é precoce - em dias longos de verão (janeiro e fevereiro) - e a cultivar Xaraés apresenta florescimento tardio - em dias curtos de outono (maio e junho) (Valle et al., 2004). A cultivar Marandu não depende do fotoperíodo para florescer (Embrapa, 1984), assim foram observados vários florescimentos esparsos do final da primavera até o início do outono. Sabe-se que em gramíneas forrageiras, o alongamento do colmo, ocorre, geralmente, concomitante ao florescimento. Nesse período, há decréscimos na relação LF:Co, pois além do crescimento do colmo ser maior, o aparecimento de folhas cessa após o aparecimento da inflorescência. Esse fato explica as maiores percentagens de colmo nos pastos da cultivar Piatã, durante o período das águas, e da cultivar Xaraés, durante o período seco (Tabela 1).

Não foram observadas diferenças entre cultivares $(p=0,22)$ e a interação envolvendo os efeitos de cultivar e período do ano $(\mathrm{p}=0,14)$ para a relação LF:MM. No entanto, essa relação durante o período das águas foi maior $(\mathrm{p}<0,01)$ do que no período seco; as médias foram $2 \pm 0,11$ e $0,5 \pm 0,13$, respectivamente. Esse acúmulo de $\mathrm{MM}$ e conseqüente alteração na relação LF:MM, durante a estação de crescimento, está associado a senescência natural da planta forrageira, ao manejo adotado, além de ser acelerada pelo deficit hídrico (Figura 2). Decréscimos semelhantes a esses foram observados em cinco cultivares de Brachiaria brizantha, sob crescimento livre, por Rodrigues (2004), e na cultivar Marandu sob lotação contínua, por Euclides et al. (2000).

Independentemente da cultivar, os pastos apresentaram maiores $(p=0,01)$ PLF e menores $(\mathrm{p}=0,01)$ PMM no período das águas, quando comparados ao período seco (Tabela 1). O decréscimo na relação LF:MM foi muito maior, apesar dos decréscimos observados na relação LF:Co dos pastos do período das águas para o da seca.

Nas características do resíduo de forragem pós-pastejo, não foram observadas diferenças nas massas de matéria seca (MMS) $(p=0,09)$, entre as cultivares e entre período do ano $(p=0,38)$. Também não houve interações entre cultivar e período do ano $(p=0,87)$, e entre cultivar e ano experimental $(p=0,66)$. No entanto, houve efeito do ano experimental $(\mathrm{P}=0,02)$ para a MMS, sendo as médias de 3.160, 3.285 e 3.060 $\mathrm{kg} \mathrm{ha}^{-1}$, respectivamente, para o primeiro, segundo e terceiro anos. Sugerindo, desta forma, que o ajuste semanal das taxas de lotação foi adequado para manter resíduos semelhantes de MMS entre tratamentos, ao longo do ano. O que está de acordo com a observação feita por Matthews et al. (1999), em que sistemas de pastejo podem adaptar-se aos padrões de produção sazonal de forragem, mas as variações existentes entre anos são mais difíceis de serem ajustadas. Respostas semelhantes foram observadas para as massas de MSLF e as PLF nos resíduos (Tabela 2), exceto para o período do ano $(\mathrm{p}=0,01)$, sendo as médias de $835 \pm 29$ e $450 \pm 34 \mathrm{~kg} \mathrm{ha}^{-1}$; e de $26,6 \pm 0,9$ e $14,5 \pm 1,1 \%$, para o período das águas e para o período seco, respectivamente. Para essas duas variáveis, os resíduos foram semelhantes $(p=0,12)$ entre os anos experimentais.

Para as PCo e PMM foram observadas diferenças entre cultivares $(p<0,02)$, período do ano $(p<0,01)$ e a interação $(p<0,05)$ entre esses dois efeitos (Tabela 2). Os resíduos com maior PCo e menor PMM foram observados: para a cultivar Piatã - durante o período das águas; e para a cultivar Xaraés - durante o período seco-, acompanhando as mesmas variações observadas para esses componentes estruturais do dossel no pré-pastejo (Tabela 1). 
Tabela 2. Médias dos quadrados mínimos e os erros-padrão da média (EPM) para as massas de matéria seca (MMS) e de matéria seca de lâminas foliares (MSLF), e as percentagens de lâminas foliares (LF), de colmos (Co) e de material morto (MM), nos resíduos dos pastos de $B$. brizantha cultivares Marandu, Xaraés e Piatã, de acordo com o período do ano ${ }^{(1)}$.

\begin{tabular}{|c|c|c|c|c|c|c|c|c|}
\hline \multirow{2}{*}{ Variável } & \multicolumn{4}{|c|}{ Período das águas } & \multicolumn{4}{|c|}{ Período seco } \\
\hline & Marandu & Piatã & Xaraés & EPM & Marandu & Piatã & Xaraés & EPM \\
\hline $\operatorname{MMS}\left(\mathrm{kg} \mathrm{ha}^{-1}\right)$ & $3.125 \mathrm{a}$ & $3.200 \mathrm{a}$ & $3.280 \mathrm{a}$ & 42,6 & $3.090 \mathrm{a}$ & $3.115 \mathrm{a}$ & $3.215 \mathrm{a}$ & 50,4 \\
\hline $\operatorname{MSLF}\left(\mathrm{kg} \mathrm{ha}^{-1}\right)$ & $760 \mathrm{a}$ & $900 \mathrm{a}$ & $850 \mathrm{a}$ & 40,7 & $360 \mathrm{a}$ & $500 \mathrm{a}$ & $485 \mathrm{a}$ & 48,2 \\
\hline LF (\%) & $24,2 \mathrm{a}$ & $29,9 \mathrm{a}$ & $25,8 \mathrm{a}$ & 0,99 & $11,7 \mathrm{a}$ & $16,5 \mathrm{a}$ & $15,3 \mathrm{a}$ & 1,17 \\
\hline Co $(\%)$ & $28,3 b$ & $37,0 \mathrm{a}$ & $34,8 \mathrm{a}$ & 0,72 & $22,5 b$ & $24,8 \mathrm{ab}$ & $30,5 \mathrm{a}$ & 0,85 \\
\hline MM (\%) & $46,7 \mathrm{a}$ & $33,1 \mathrm{~b}$ & $39,5 \mathrm{ab}$ & 1,17 & $65,8 \mathrm{a}$ & $58,7 \mathrm{ab}$ & $54,1 \mathrm{~b}$ & 1,38 \\
\hline
\end{tabular}

${ }^{(1)}$ Médias seguidas de letras iguais na linha, dentro de período do ano, não diferem entre si pelo teste de Tukey, a 5\% de probabilidade.

Durante o período das águas, independentemente da cultivar, os desaparecimentos de MMS e de MSLF, do pré para o pós-pastejo, foram, em média, de 884 e $833 \mathrm{~kg} \mathrm{ha}^{-1}$, respectivamente. No período seco, dos $626 \mathrm{~kg} \mathrm{ha}^{-1}$ de MMS desaparecidos, do pré para o pós-pastejo, 325 e $282 \mathrm{~kg} \mathrm{ha}^{-1}$, foram, respectivamente, de MSLF e MS de colmo (Tabelas 1 e 2). Sugerindo, desta forma, que a estrutura do dossel, durante o período das águas, foi favorável ao pastejo seletivo. E durante o período seco, os animais tiveram maiores dificuldades na seleção e na preensão da forrageira, uma vez que altas proporções de colmo e/ou material morto podem limitar o consumo, mesmo quando a disponibilidade de matéria seca é alta (Tabela 1).

\section{Conclusões}

1. As principais diferenças nas estruturas dos dosséis são acúmulo de colmo e, conseqüentemente, redução na relação lâmina foliar:colmo, na cultivar Piatã no período das águas, e na cultivar Xaraés no período seco, o que sugere que o manejo do pastejo deve ser diferenciado para essas cultivares.

2. À semelhança da cultivar Marandu, as cultivares Xaraés e Piatã são bem adaptadas aos solos do Cerrado e são excelentes alternativas para a diversificação de forragem.

\section{Agradecimentos}

À Fundação de Apoio ao Desenvolvimento do Ensino, Ciência e Tecnologia do Estado de Mato Grosso do Sul, pelo financiamento parcial do experimento; ao Conselho Nacional de Desenvolvimento Científico e Tecnológico, pelas bolsas concedidas; ao Sr. Marcelo Paschoal de Oliveira, pela ajuda na condução do experimento.

\section{Referências}

ALCÂNTARA, P.B.; PEDRO JÚNIOR, M.; DONZELLI, P.L. Zoneamento edafoclimático de plantas forrageiras. In: SIMPÓSIO SOBRE ECOSSISTEMA DE PASTAGENS, 2., 1993, Jaboticabal. Anais. Jaboticabal: Funep, 1993. p.1-16.

ANDRADE, R.P. de; VALENTIM, J.F. A síndrome da morte do capim-braquiarão. Piracicaba: Beefpoint, 2004. Disponível em: $<$ http://www.beefpoint.com.br/?noticiaID=19859\&actA=7\&areaID= 60\&secaoID=177>. Acesso em: 11 fev. 2006.

BARBOSA, R.A. (Ed.). Morte de pastos de braquiárias. Campo Grande: Embrapa Gado de Corte, 2006. 206p.

BRÂNCIO, P.A.; NASCIMENTO JÚNIOR, D. do; EUCLIDES, V.P.B.; FONSECA, D.M. da; ALMEIDA, R.G. de; MACEDO, M.C.M.; BARBOSA, R.A. Avaliação de três cultivares de Panicum maximum Jácq. sob pastejo: composição da dieta, consumo de matéria seca e ganho de peso animal. Revista Brasileira de Zootecnia, v.32, p.1037-1044, 2003.

DIAS-FILHO, M.B.; ANDRADE, C.M.S. de. Pastagens no ecossistema do trópico úmido. In: SIMPÓSIO SOBRE PASTAGENS NOS ECOSSISTEMAS BRASILEIROS, 2., 2005, Goiânia. Anais. Goiânia: SBZ, 2005. p.95-104.

EMBRAPA. Brachiaria brizantha cv. Marandu. Campo Grande: Embrapa-CNPGC, 1984. 31p. (Embrapa-CNPGC. Documentos, 21).

EMBRAPA. Manual de métodos de análise de solo. 2.ed. Brasília: Embrapa-SPI; Rio de Janeiro: Embrapa-CNPS, 1997. 212p.

EMBRAPA. Sistema brasileiro de classificação de solos. Brasília: Embrapa-SPI; Rio de Janeiro: Embrapa-CNPS, 1999. 412p.

EUCLIDES, V.P.B.; CARDOSO, E.G.; MACEDO, M.C.M.; OLIVEIRA, M.P. Consumo voluntário de Brachiaria decumbens cv. Basilisk e Brachiaria brizantha cv. Marandu sob pastejo. Revista Brasileira de Zootecnia, v.29, p.2200-2208, 2000.

EUCLIDES, V.P.B.; COSTA, F.P.; MACEDO, M.C.M.; FLORES, R.; OLIVEIRA, M.P. de. Eficiência biológica e econômica de pasto de capim-tanzânia adubado com nitrogênio no final do verão. Pesquisa Agropecuária Brasileira, v.42, p.1345-1355, 2007.

EUCLIDES, V.P.B.; EUCLIDES FILHO, K. Uso de animais na avaliação de forrageiras. Campo Grande: Embrapa-CNPGC, 1998. 59p. (Embrapa-CNPGC. Documentos, 74).

EUCLIDES, V.P.B.; MACEDO, M.C.M.; ZIMMER, A.H.; JANK, L.; OLIVEIRA, M.P. de. Avaliação dos capins mombaça e massai 
sob pastejo. Revista Brasileira de Zootecnia, v.37, p.18-26, 2008 .

LARA, M.A.S. Respostas morfofisiológicas de cinco cultivares de Brachiaria spp. às variações estacionais da temperatura do ar e do fotoperíodo. 2007. 91p. Dissertação (Mestrado) - Escola Superior de Agricultura Luiz de Queiroz, Piracicaba.

MACEDO, M.C.M. Adubação fosfatada em pastagens cultivadas com ênfase na região dos Cerrados. In: YAMADA, T.; ABDALLA, S.R.S. (Ed.). Fósforo na agricultura brasileira. Piracicaba: Potafos, 2004. p.359-400.

MACEDO, M.C.M. Pastagens no ecossistema cerrados: evolução das pesquisas para o desenvolvimento sustentável. In: REUNIÃO ANUAL DA SOCIEDADE BRASILEIRA DE ZOOTECNIA, 42., 2005, Goiânia. A produção animal e o foco no agronegócio: anais. Goiânia: SBZ, 2005. p.56-84.

MACEDO, M.C.M. Sustainability of pasture production in the Savannas of Tropical America. In: INTERNATIONAL GRASSLAND CONGRESS, 18., Winnipeg, 1997. Proceedings. Winnipeg: Canadian Grassland Association, 1997. v.4. p.7-16.

MALAVOLTA, E.; VITTI, C.G.; OLIVEIRA, S.A. Avaliação do estado nutricional das plantas: princípios e aplicações. Piracicaba: Potafos, 1997. 319p.

MATTHEWS, P.N.P.; HARRINGTON, K.C.; HAMPTON, J.G. Management of grazing systems. In: WHITE, J.; HODGSON, J. (Ed.). New Zealand pasture crop science. Auckland: Oxford University Press, 1999. p.153-174.

MONTEIRO, F.A. Amostragem de solo e planta para fins de análises químicas: métodos e interpretação de resultados. In: SIMPÓSIO SOBRE MANEJO DA PASTAGEM, 22., 2005, Piracicaba. Anais. Piracicaba: Fealq, 2005. p.151-179.

PEDREIRA, B.C. e; PEDREIRA, C.G.S.; SILVA, S.C. da. Estrutura do dossel e acúmulo de forragem de Brachiaria brizantha cultivar Xaraés em resposta a estratégias de pastejo. Pesquisa Agropecuária Brasileira, v.42, p.281-287, 2007.

REGO, F.C. de A.; DAMASCENO, J.C.; MARTINS, E.N.; CORTES, C.; FUKUMOTO, N.M.; ROESHI, L.; SANTOS, G.T. dos. Influência de variáveis químicas e estruturais do dossel sobre a taxa de ingestão instantânea em bovinos manejados em pastagens tropicais. Revista Brasileira de Zootecnia, v.35, p.691-698, 2006.

RODRIGUES, D. de C. Produção de forragem de cultivares de Brachiaria brizantha (Hochst ex A. Rich) Stapf e modelagem de respostas produtivas em função de variáveis climáticas. 2004. 94p. Dissertação (Mestrado) - Escola Superior de Agricultura Luiz de Queiroz, Piracicaba.

SAS INSTITUTE. SAS/STAT: user's guide statistics: versão 6.4 . Cary: SAS Institute, 1996.

VALLE, C.B. do; EUCLIDES, V.P.B.; MACEDO, M.C.M. Características das plantas forrageiras do gênero Brachiaria. In: SIMPÓSIO SOBRE MANEJO DA PASTAGEM, 17., Piracicaba, 2000. Anais. Piracicaba: Fealq, 2000. p.65-108.

VALLE, C.B. do; EUCLIDES, V.P.B.; PEREIRA, J.M.; VALÉRIO, J.R.; PAGLIARINI, M.S.; MACEDO, M.C.M.; LEITE, G.G.; LOURENÇO, A.J.; FERNANDES, C.D.; DIAS-FILHO, M.B.; LEMPP, B.; POTT, A.; SOUZA, M.A. de. O capim-xaraés (Brachiaria brizantha cv. Xaraés) na diversificação das pastagens de braquiárias. Campo Grande: Embrapa Gado de Corte, 2004. 36p. (Embrapa Gado de Corte. Documentos, 149).

VALLE, C.B. do; MILES, J.W. Melhoramento de gramíneas do gênero Brachiaria. In: SIMPÓSIO SOBRE MANEJO DA PASTAGEM, 11., 1994, Piracicaba. Anais. Piracicaba: Fealq, 1994. p.1-24.

VILELA, L.; SOARES, W.V.; SOUSA, D.M.G. de; MACEDO, M.C.M. Calagem e adubação para pastagens. In: SOUSA, D.M.G.; LOBATO, E. (Ed.). Cerrado: correção do solo e adubação. 2.ed. Planaltina: Embrapa Cerrados, 2004. p.367-382.

ZEFERINO, C.V. Morfogênese e dinâmica do acúmulo de forragem em pastos de capim-marandu [Brachiaria brizantha (Hoechst. ex A. Rich) cv. Marandu] submetidos a regimes de lotação intermitente por bovinos de corte. 2006. 193p. Dissertação (Mestrado) - Escola Superior de Agricultura Luiz de Queiroz, Piracicaba.

Recebido em 11 de julho de 2008 e aprovado em 27 de outubro de 2008 